\title{
Synthesis, Characterization, and DNA Binding Studies of Nanoplumbagin
}

\author{
Sheik Dawood Shahida Parveen, ${ }^{1}$ Abdullah Affrose, ${ }^{1}$ Basuvaraj Suresh Kumar, ${ }^{1}$ \\ Jamespandi Annaraj, ${ }^{1}$ and Kasi Pitchumani ${ }^{1,2}$ \\ ${ }^{1}$ School of Chemistry, Madurai Kamaraj University, Madurai 625021, India \\ ${ }^{2}$ Centre for Green Chemistry Processes, School of Chemistry, Madurai Kamaraj University, Madurai 625021, India
}

Correspondence should be addressed to Kasi Pitchumani; pit12399@yahoo.com

Received 14 August 2014; Revised 8 November 2014; Accepted 10 November 2014; Published 17 December 2014

Academic Editor: Zhi Li Xiao

Copyright ( 2014 Sheik Dawood Shahida Parveen et al. This is an open access article distributed under the Creative Commons Attribution License, which permits unrestricted use, distribution, and reproduction in any medium, provided the original work is properly cited.

\begin{abstract}
The traditional anticancer medicine plumbagin (PLN) was prepared as nanostructured material (nanoplumbagin, NPn1) from its commercial counterparts, simultaneously coencapsulating with cetyltrimethylammonium bromide or cyclodextrin as stabilizers using ultrasonication technique. Surface morphology of NPn analysed from atomic force microscopy (AFM) indicates that NPn has tunable size between $75 \mathrm{~nm}$ and $100 \mathrm{~nm}$ with narrow particle size distribution. Its binding efficiency with herring sperm DNA was studied using spectral and electrochemical techniques and its efficiency was found to be more compared to the commercial microcrystalline plumbagin (PLN). DNA cleavage was also studied by gel electrophoresis. The observed results indicate that NPn1 has better solubility in aqueous medium and hence showed better bioavailability compared to its commercial counterparts.
\end{abstract}

\section{Introduction}

Though traditional medicines are generally claimed to be safe and efficacious, in most cases neither the chemical entity nor the molecular mechanism of action is well defined. Plumbagin (5-hydroxy-2-methyl-1,4-naphthoquinone), a quinonoid constituent isolated from the root of Plumbago zeylanica L., has been shown to exert anticarcinogenic, antiatherosclerotic, and antimicrobial effects [1-3]. Oral administration of drugs is the most popular route for the majority of drugs. However when drugs are poorly soluble, they have low bioavailability due to their inherent low solubility and slow dissolution rate primarily in the gastrointestinal tract, which necessitates highly concentrated administration of drugs than normally needed. Many synthesized anticancer drugs exert their cytotoxicity by inhibiting DNA synthesis and cell replication [4]. The side effects of these drugs such as bone marrow suppression and gastrointestinal toxicity are difficult to avoid. In this context, nanoencapsulation of drug particles is a useful technique in controlled and targeted delivery [5-7]. During the past few decades, a large variety of biocompatible drug delivery systems such as liposomes, micelles, emulsions, and polymeric micro- and nanoparticles have been developed. Polyelectrolyte capsules were also identified as promising drug delivery vehicles $[8,9]$. In this context, nanoparticles can be considered as useful platforms as they have unique advantages such as high surface area to volume ratio and allow many functional groups to be attached to a nanoparticle, which can seek out and bind to selected tumor cells. Additionally, the small size of nanoparticles allows them to preferentially accumulate at tumor sites. Dissolution rates may increase by reducing the particle size to increase the interfacial surface area [10].

To overcome the problems of using bulk materials as drugs, nanoparticle based drug delivery approaches were developed [11], in which curcumin is encapsulated in liposomes [12], solid lipid microparticles, such as bovine serum albumin [13] and chitosan [14], or complexed with phospholipids [15] and cyclodextrin [16-19]. Currently, the sonochemical method has been used extensively to generate novel 
materials with unusual properties, since they form particles of a much smaller size and higher surface area than those reported by other methods [20,21].

Cetyltrimethylammonium bromide (CTAB) is a wellknown surfactant and has been widely used in the synthesis of many types of nanoparticles with controlled morphologies $[22,23]$. Using this cationic surfactant, a rich variety of aggregate microstructures can be synthesised even at high dilution and; this can serve as novel organic templates for mesostructured materials with various remarkable morphologies.

Recently, cyclodextrins (CDs) were found to play important roles in self-assembly systems of amphiphiles or surfactants. As an amphiphilic building unit, CDs can be chemically or physically attached to a hydrophobic moiety, where the CD outer surface acts as a hydrophilic moiety and the resultant compound as a classic amphiphile. The amphiphilic CDs can self-assemble in a classic way similar to that of surfactant, where the $\mathrm{CD}$ portion acts like the hydrophilic head group of a surfactant [24]. Many amphiphilic CDs were developed and were found to be able to form micelles, monolayers at air/water surface, vesicles, and fibers. Compared to surfactant aggregates, the amphiphilic $\mathrm{CD}$-based aggregates can provide macrocyclic hosting sites on the surface, creating new possibilities for host-guest interaction and recognition.

The principle of ultrasonication is based on formation, growth, and implosion of acoustic cavity and is considered as a green, simple, fast, popular, and reproducible method. In this study, we have used low frequency ultrasonication process for the synthesis of NPn using CTAB or $\beta-\mathrm{CD}$ as a surfac$\operatorname{tant} /$ stabilizers. It was characterized using FT-IR and UV-Vis spectroscopy, AFM and scanning electron microscopy (SEM) and DLS techniques. Their interaction with DNA was also investigated through spectral and electrochemical studies.

\section{Experimental Techniques}

2.1. Materials and Methods. Plumbagin, cetyltrimethylammonium bromide (CTAB), and $\beta$-cyclodextrin $(\beta-\mathrm{CD})$ were purchased from Sigma Aldrich. pUC18 DNA from SRL, Herring sperm DNA (hs-DNA) from GENEI, and sodium chloride and Tris hydrochloride (Tris-HCl) were purchased from Merck. All other chemicals were used without further purification. Double distilled water was used throughout the experimental studies. All the experimental studies involving the interaction of the plumbagin (PLN) and nanoplumbagin (NPn) with hs-DNA were carried out in aerated buffer (Tris$\mathrm{HCl}, \mathrm{pH}$ 7.1) containing $\mathrm{NaCl}$. Gel electrophoresis experiments were performed using pUC18-DNA and 1\% agarose gels together with a TAE (Tris-acetic acid-EDTA) running buffer solution. DNA samples were mixed with loading dye (bromophenol blue) and loaded into the slots of the submerged gel and resolved at $50 \mathrm{~V}$. The gels were photographed under UV light.

2.2. Physical Measurements. UV-Vis absorption spectra were recorded using JASCO-spectra manager (V-550) in $1 \mathrm{~cm}$ path length quartz cuvette with a volume of $2 \mathrm{~mL}$ at $25^{\circ} \mathrm{C}$. Infrared spectra of PLN and NPn were recorded on a JASCO FT-IR$410\left(4000-400 \mathrm{~cm}^{-1}\right)$ spectrophotometer. The SEM images were obtained using a JEOL JSM-6390 scanning electron microscope. The powder samples were placed over carbon tape and a thin layer of platinum was coated over the samples to avoid charging. Cyclic voltammetric measurements were carried out on a Bioanalytical System (BAS) model CV-50W electrochemical analyzer. The three-electrode cell comprised a reference $\mathrm{Ag} / \mathrm{AgCl}$, platinum wire as counter electrode and working glassy carbon (GC) electrodes with surface area of $0.07 \mathrm{~cm}^{2}$. The GC was polished with 0.3 and $0.05 \mathrm{~mm}$ alumina before each experiment and if necessary the electrode was sonicated in distilled water for $10 \mathrm{~min}$. Dissolved oxygen was removed by purging the solution with pure nitrogen gas for about $15 \mathrm{~min}$ before each experiment. A bare cyclic voltammogram has been carried out for a blank solution to check the purity of the supporting electrolyte and the solvent. Nuclear magnetic resonance spectroscopic measurements were recorded using Bruker $300 \mathrm{MHz}$ spectrometer. Circular dichroism spectra were recorded on a JASCO J-810 (200$900 \mathrm{~nm}$ ) spectropolarimeter. The spectral changes of PLN and NPn during the addition of increasing concentration of DNA were monitored at $25^{\circ} \mathrm{C}$ using a quartz cuvette of $1 \mathrm{~cm}$ optical path length with a volume of $1 \mathrm{~mL}$ at room temperature. Gel electrophoretograms of the samples were investigated by BIORAD Model XI computer controlled electrophoresis power supply.

2.3. Preparation of Nanoplumbagin (NPn). Commercially available microcrystalline plumbagin $(0.094 \mathrm{~g}, 0.5 \mathrm{mM})$ was dissolved in $5 \mathrm{~mL}$ of ethanol and poured into $\mathrm{HCl}(0.05 \mathrm{M}$, $20 \mathrm{~mL})$. An aqueous solution of $\mathrm{NaOH}(0.05 \mathrm{M}, 20 \mathrm{~mL})$ was prepared separately in presence of $\mathrm{CTAB}$ or $\beta$-cyclodextrin. Then two different concentrations of 0.2 and $0.5 \mathrm{wt} \%$ of CTAB and $\beta$-cyclodextrin were prepared, the dropwise addition of plumbagin solution into $\mathrm{CTAB} / \beta$-cyclodextrin solution in $\mathrm{NaOH}$ is effected separately under ultrasonic conditions, using an ultrasonic power of $250 \mathrm{w}$ and a frequency of $59 \mathrm{~Hz}$. After sonication for $40 \mathrm{~min}$, yellow precipitate was obtained which was washed with ethanol several times to remove unbounded surfactants (CTAB or $\beta-\mathrm{CD})$ to give pure nanoplumbagin. It was characterized by UV-Vis, absorption, FT-IR, and ${ }^{1} \mathrm{H}$ NMR spectroscopy techniques. The absorption data clearly showed the enhanced solubility of NPn1 in water, compared to an equivalent concentration of Pn. Further, these spectral data also confirm that NPn does not undergo any structural change during its synthesis from its commercial counterparts. It was characterised by UVVis, ${ }^{1} \mathrm{H} \&{ }^{13} \mathrm{C}-\mathrm{NMR}$, and FT-IR spectra. IR $\left(\nu, \mathrm{cm}^{-1}, \mathrm{KBr}\right)$ : $v(\mathrm{O}-\mathrm{H})=3412 \mathrm{~nm}, v(\mathrm{C}=\mathrm{O})=1664 \mathrm{~nm}, 1643 \mathrm{~nm}, v(-$ $\left.\mathrm{CH}_{3}\right)=2922 \mathrm{~nm}, \mathrm{UV}-\mathrm{Vis}(\mathrm{DMSO}): \lambda_{\max }=416 \mathrm{~nm} .{ }^{1} \mathrm{H}$ NMR $\left(300 \mathrm{MHz}, \mathrm{CDCl}_{3}\right) \delta$ ppm $12(1 \mathrm{H}), 7.8(2 \mathrm{H}), 7.3(1 \mathrm{H}), 7.2$ $(1 \mathrm{H}), 6.8(1 \mathrm{H}), 2.2(3 \mathrm{H}) .{ }^{13} \mathrm{C} \mathrm{NMR}\left(\mathrm{CDCl}_{3}, 75 \mathrm{MHz}\right) \delta \mathrm{ppm}$ 190, 184, 161, 149, 136, 133, 124, 119 and 16. (Figures S1, S2, and S3 in SI) (see Supplementary Material available online at http://dx.doi.org/10.1155/2014/179149). The schematic representation of the synthesis is shown in Scheme 1. 


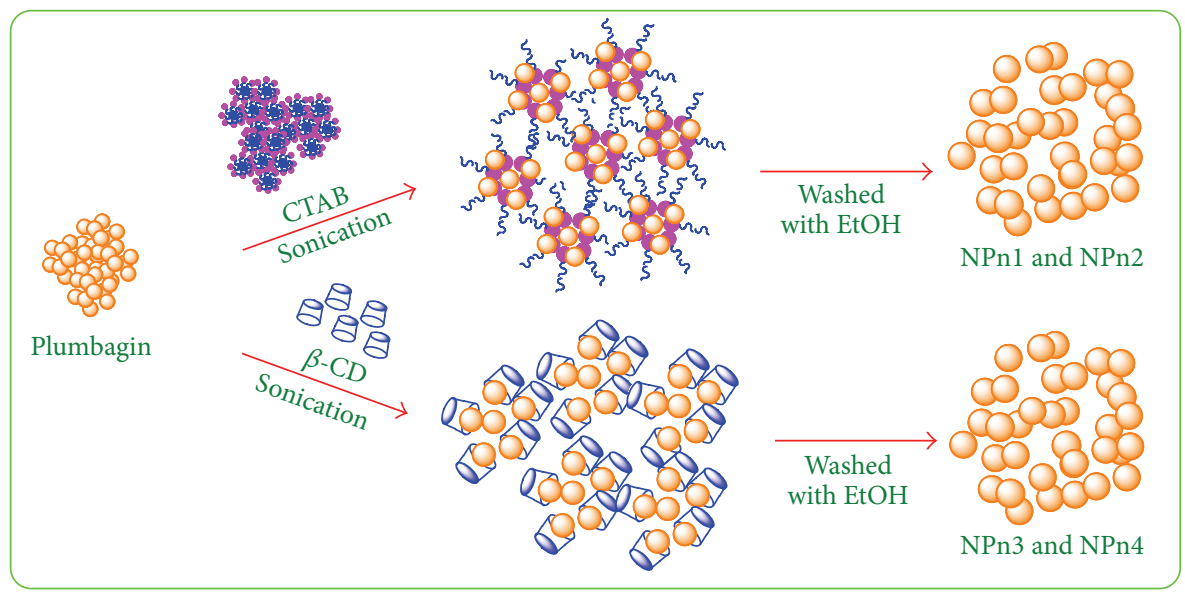

SCHEME 1: Schematic representation of the synthesis of NPn.

2.4. Preparation of Stock Solution of Nanoplumbagin. All the measurements were carried out in Tris-hydrochloride buffer at $\mathrm{pH} 7.1$ and double distilled water was used to prepare buffers. The stock solution of nanoplumbagin $\left(1 \times 10^{-2} \mathrm{M}\right)$ was prepared by dissolving $0.094 \mathrm{~g}$ of nanoplumbagin (NPn1) in $50 \mathrm{~mL}$ Tris-hydrochloride buffer at $\mathrm{pH}$ 7.1.

\section{Results and Discussion}

\subsection{Characterization of Nanoplumbagin (NPn)}

3.1.1. DLS Data Analysis. The analysis of dynamic light scattering data of NPn1 given in supporting information (Figure S4) showed that Npn1 has the particle size ranging from $7 \mathrm{~nm}$ to $1200 \mathrm{~nm}$ with most of the particles lying in the range of $75 \mathrm{~nm}-110 \mathrm{~nm}$.

3.1.2. Atomic Force Microscopy (AFM). The effect and the amount of stabilizers were taken into account during the synthesis of NPn, namely, NPn1-NPn4. AFM images and size distribution of the NPn prepared in presence of 0.2 and 0.5 wt $\%$ CTAB, namely, NPn1 and NPn2, respectively, are shown in Figure 1. From this data it is clear that in NPn1, the nanoparticles are in the range of 84-110 nm (Figure 1(a)) with the height profile of the three-dimensional (3D) AFM image (Figure 1(b)) of NPn1 found to be about $10.9 \mathrm{~nm}$, whereas in NPn2 the microparticles are in the range of $110-350 \mathrm{~nm}$ (Figure 1(c)) with a height of $15 \mathrm{~nm}$ (Figure 1(d)) due to the fact that CTAB as stabilizer can be absorbed at the surface to control crystal growth and coagulation.

Similarly AFM images and size distribution of the NPn prepared in the presence of 0.2 and $0.5 \mathrm{wt} \% \beta-\mathrm{CD}$, namely, NPn3 and NPn4, respectively, are also shown in Figure 2. AFM images of NPn3 and NPn4 show that the particles are in the range of $110-160 \mathrm{~nm}$ with the height of $26 \mathrm{~nm}$ (Figures 2(a) and 2(b)) and 530-700 $\mathrm{nm}$ with the height of $140 \mathrm{~nm}$ (Figures $2(\mathrm{c})$ and $2(\mathrm{~d}))$, respectively.

From these observations it can be concluded that $0.2 \mathrm{wt} \%$ of CTAB, that is, NPnl, is appropriate for the preparation of
NPn, which is taken into account for further studies like DNA binding and cleavage studies.

3.1.3. SEM Analysis. The morphology of the nanocrystalline plumbagin (NPn1) was studied by scanning electron microscopic (SEM) technique. This material consisted of nanospheres with $\sim 84-110 \mathrm{~nm}$ grain size (Figure 3) which is consistent with the data obtained from AFM images and some larger sized particles present in the system are also seen in these images.

3.1.4. XRD Diffraction Pattern of NPn1. The powder X-ray diffraction pattern of NPnl is as shown in the Supporting Information (Figure S5). A definite line broadening of the XRD peaks indicates that the prepared material consists of particles which are in the nanoscale range. The diffraction peaks are observed at $2 \theta$ values $11.61^{\circ}, 13.46^{\circ}, 26.72^{\circ}, 31.94^{\circ}$, $45.62^{\circ}, 56.63^{\circ}$, and $75.4^{\circ}$, from the calculated lattice constants $a=b=3254 \AA$ and $c=5202 \AA$. The observed pattern indicates that these NPn1 nanoparticles are present as hexagonal wurtzite phase and the average crystalite size is $14.98 \mathrm{~nm}$.

\subsection{DNA Binding Studies}

3.2.1. Electronic Absorption Studies. The interaction of synthesized nanocrystalline plumbagin with herring sperm DNA was investigated by monitoring the changes observed in the UV-Vis absorption bands $\left(\pi \rightarrow \pi^{*}\right.$ and $n \rightarrow \pi^{*}$ transitions). When increasing the concentration of herring sperm DNA to a constant concentration of nanodrug caused a hypochromism in their UV-Vis absorption bands along with a slight red shift (2-5 nm) (Figure 4 and Table 1 in SI), which indicates the possibility of deep penetration of NPn1 particles into the core of DNA. In contrast PLN showed no change in its absorption measurements (Figure 5) due to its poor or no solubility in aqueous medium. These results show that the main action mode of NPn1 binding to DNA is intercalation $[25,26]$. 


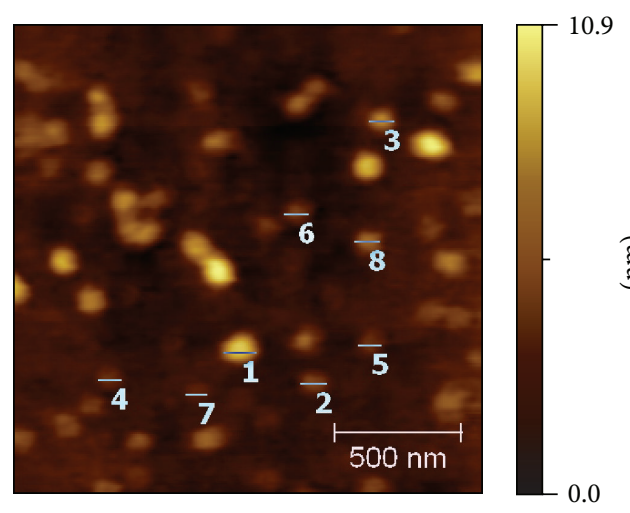

(a)

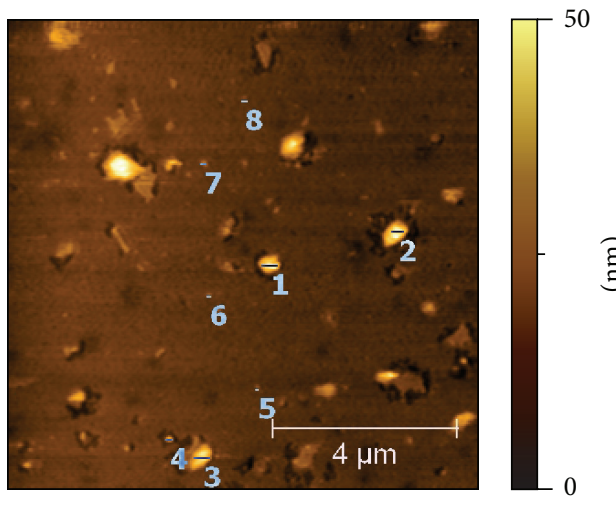

(c)

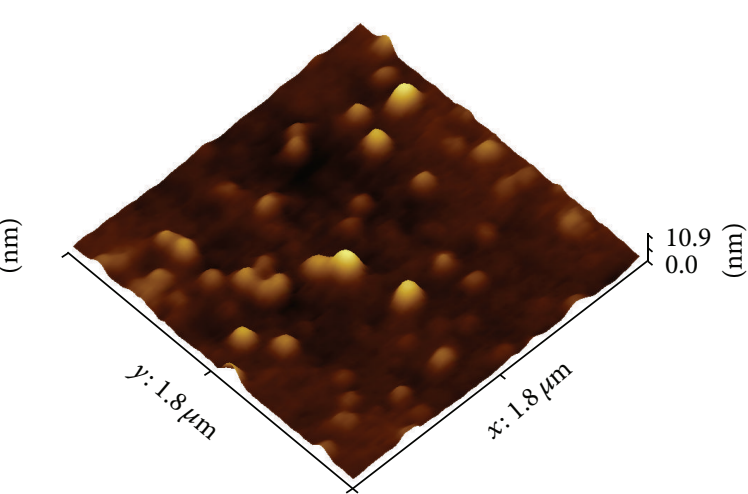

(b)

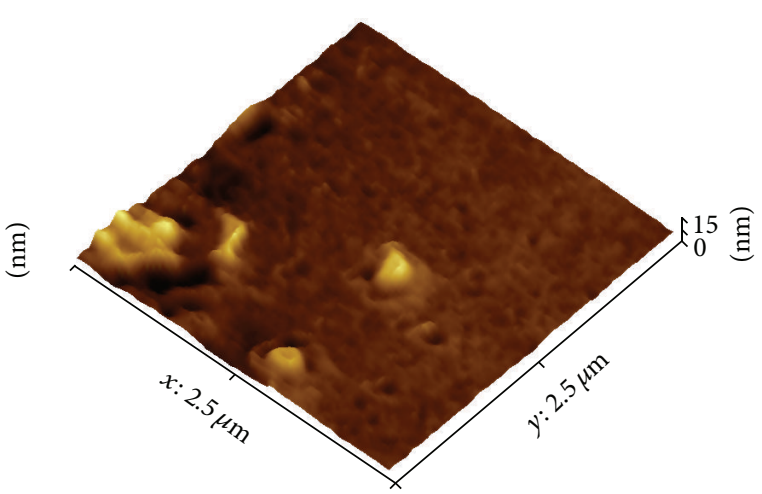

(d)

Figure 1: (a and c) Two-dimensional (2D) AFM image of NPn1 and NPn2. (b and d) Three-dimensional (3D) images of NPn1 and NPn2.

The intrinsic binding constant $K_{b}$ values were determined from a plot of [DNA]/( $\left.\varepsilon_{a}-\varepsilon_{f}\right)$ versus [DNA] using the following equation:

$$
\frac{[\mathrm{DNA}]}{\left(\varepsilon_{a}-\varepsilon_{f}\right)}=\frac{[\mathrm{DNA}]}{\left(\varepsilon_{b}-\varepsilon_{f}\right)}+\frac{1}{K_{b}}\left(\varepsilon_{b}-\varepsilon_{f}\right)
$$

where [DNA] is the concentration of DNA in base pairs, $\varepsilon_{a}$ is the apparent extinction coefficient obtained by calculating $A_{\text {obs }} /$ [complex], and $\varepsilon_{f}$ and $\varepsilon_{b}$ correspond to extinction coefficients of the complex in its free and bound forms, respectively [27]. From the plots of [DNA]/( $\left.\varepsilon_{a}-\varepsilon_{f}\right)$ versus [DNA], $K_{b}$ is measured by the ratio of slope to intercept as shown in Figures 4 and 5.

The intrinsic binding constants $\left(K_{b}\right)$ for NPn1 and PLN with DNA are $2.9 \times 10^{4} \mathrm{M}^{-1}$ and $5.4 \times 10^{3} \mathrm{M}^{-1}$. The observed $K_{b}$ value for PLN closely matches with the previous report [27] and that of NPnl showed much higher value than PLN and its copper complexes due to its better solubility in aqueous medium than its counterparts. The binding constant values observed from electronic spectral results indicate that NPn1 strongly intercalates into the core DNA compared to its commercial counterparts.

3.2.2. Circular Dichroism Studies. The changes which occurred in the CD signals of the DNA upon interactions with drugs may often be assigned to the corresponding changes in the DNA structure [28]. The groove binding and electrostatic interaction of a molecules with DNA show less or no perturbations on the base stacking and helicity bands because these two binding modes do not influence the secondary structure of DNA, while the observed intensity change can be attributed to an intercalation mode when small planar molecules interact with DNA [29].

The observed ICD spectrum (Figure 6) of herring sperm DNA (hs-DNA) consists of a positive band at $275 \mathrm{~nm}$ due to base stacking and a negative band at $245 \mathrm{~nm}$ due to its helicity, which are characteristic of right-handed B form DNA [30]. Upon addition of PLN to DNA, the CD spectrum exhibits a slight alteration on both negative and positive absorption intensities without much change in its wavelength, indicating a relatively weak intercalation of plumbagin to hs-DNA. In the presence of NPnl, a significant decrease in the peak intensities of both bands was observed which indicates that NPnl can effectively intercalate the neighbouring base pairs of hs-DNA to reduce the energy of the $\pi-\pi$ electronic transition and also due to strong conformational changes by NPn1 and its binding to DNA mainly by intercalation mode [31].

3.2.3. Electrochemical Studies. The electrochemical method is extremely useful in probing the nature and mode of 


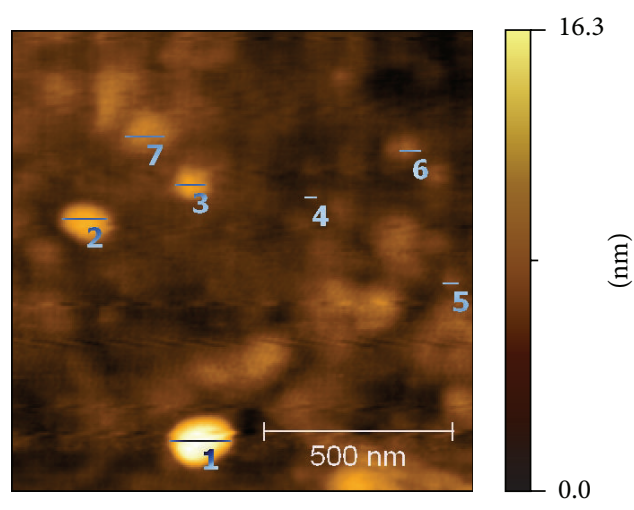

(a)

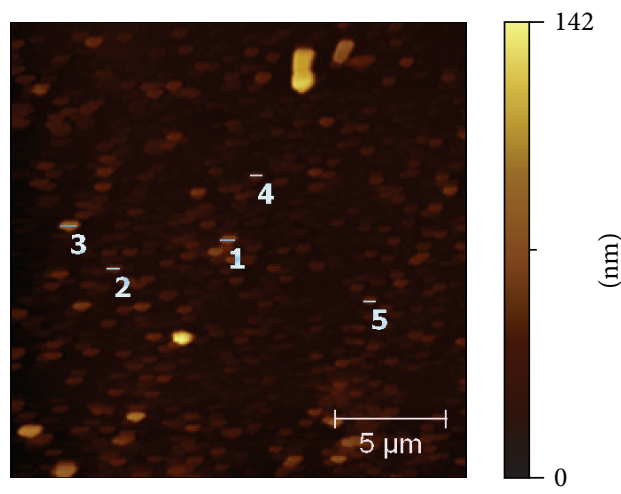

(c)

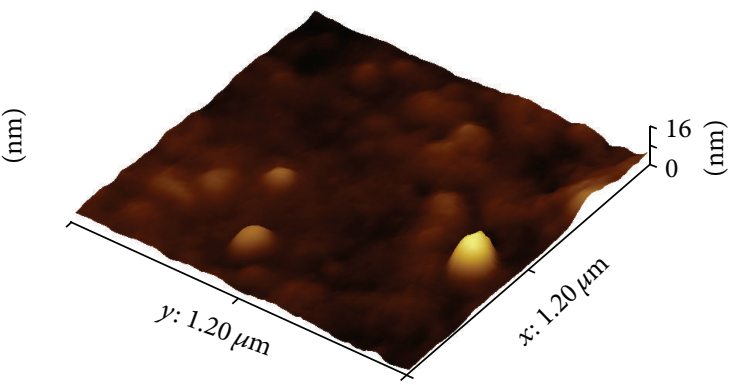

(b)

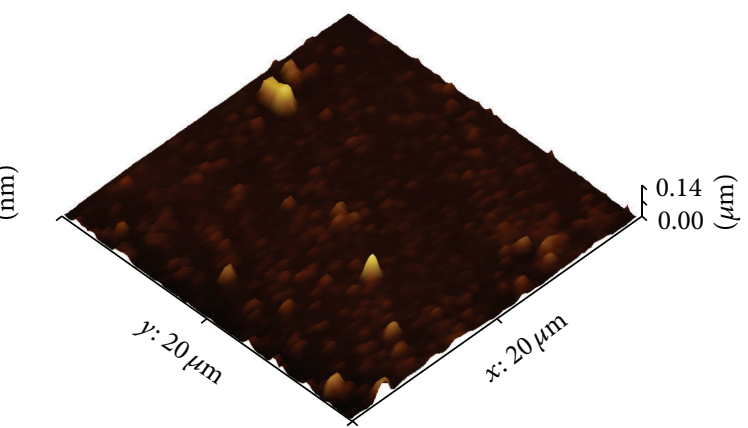

(d)

Figure 2: (a and c) Two-dimensional (2D) AFM image of NPn3 and NPn4. (b and d) Three-dimensional (3D) images of NPn3 and NPn4.
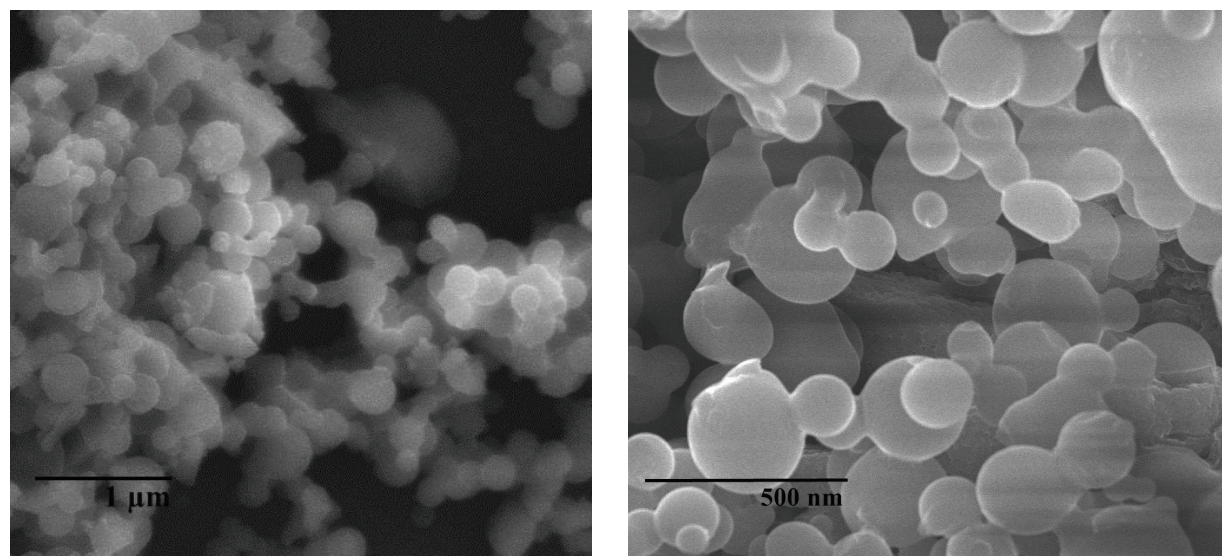

FIGURE 3: SEM images of nanoplumbagin (NPn1).

DNA binding with metal complexes. Cyclic voltammetric behaviour of NPn1 and PLN in the absence and presence of DNA is shown in Figures $7(\mathrm{a})$ and $7(\mathrm{~b})$. The separation of the cathodic and anodic peak potentials, $\Delta E_{p}$, and the ratio of cathodic to anodic peak current, $i_{p a} / i_{p c}$ (Table 2 in SI), indicate that the quasi-reversible redox process was observed for both NPn1 and PLN. The formal potential $E^{0 \prime}$ (or voltammetric $E_{1 / 2}$ ), taken as the average of $E_{p c}$ and $E_{p a}$, in the absence of DNA for NPnl and PLN is -0.311 and $-0.289 \mathrm{mV}$, respectively, which upon the addition of DNA undergo a slight positive shift, indicating significant association of NPn1 and PLN with DNA [32].

It is reported by Bard and Faulkner [33] that if the peak potential is shifted negatively when the molecule interacted with DNA, the interaction will be electrostatic in nature. On the contrary, if the peak potential is shifted positively, the interaction will be through intercalation mode. If there is no change of peak potential, then the interaction of the reduced 


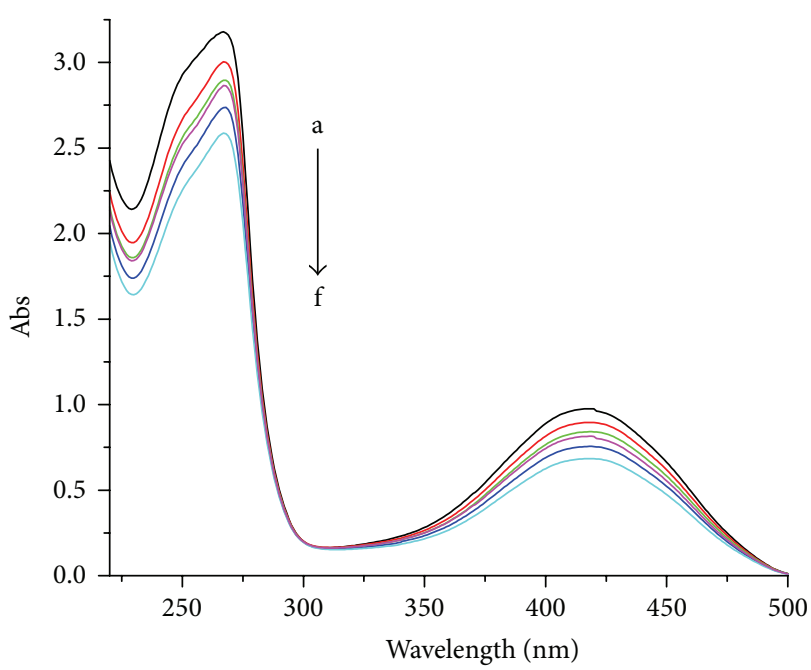

(a)

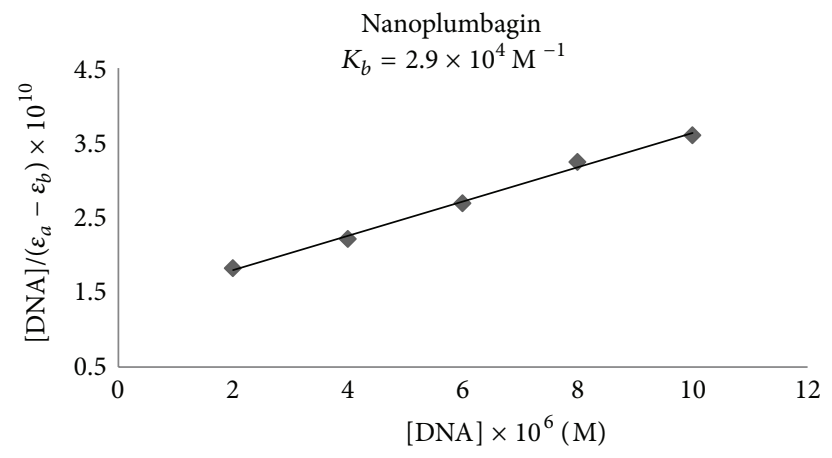

(b)

Figure 4: UV-Vis spectrum of NPn1 $\left(1 \times 10^{-4} \mathrm{M}\right)$ in $5 \mathrm{mM}$ Tris- $\mathrm{HCl}$ buffer at $\mathrm{pH} 7.1$ with increasing amounts of DNA. (a) $R=0$; (b) $R=0.2$; (c) $R=0.4$; (d) $R=0.6$; (e) $R=0.8$; and (f) $R=1 . R=[\mathrm{DNA}] /[$ compound].

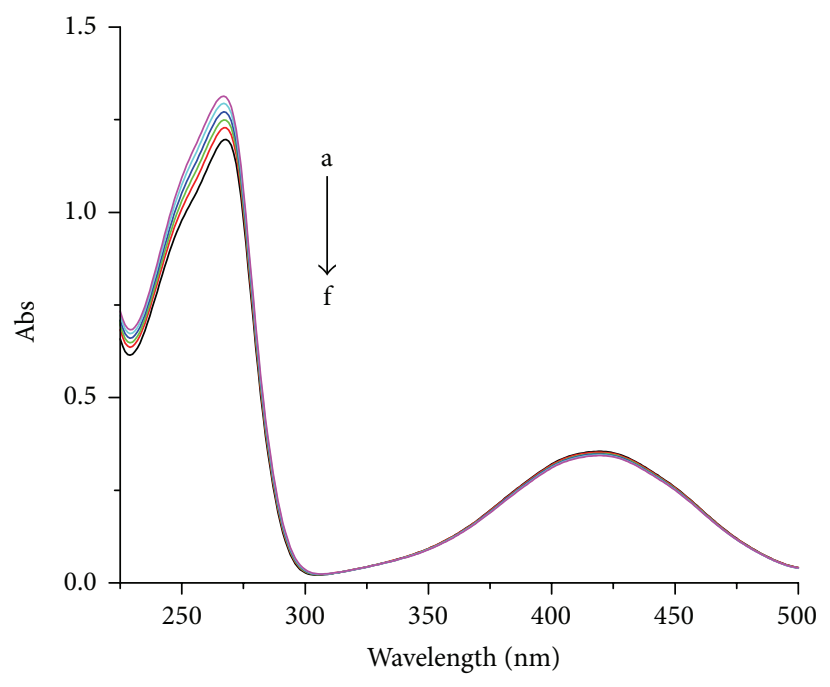

(a)

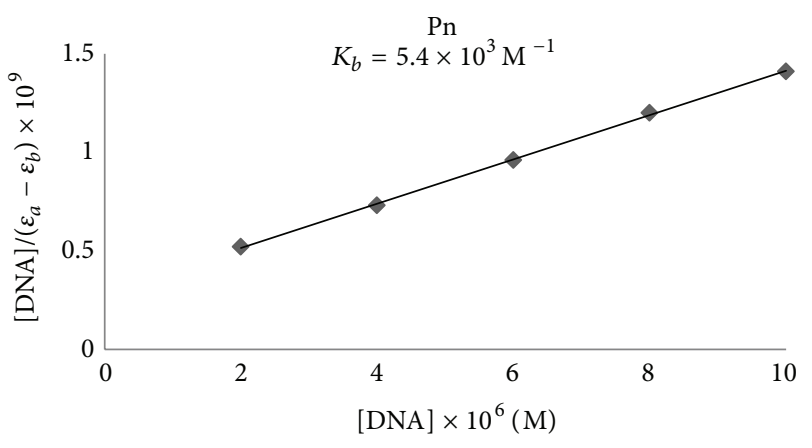

(b)

FIGURE 5: UV-Vis spectrum of PLN $\left(1 \times 10^{-4} \mathrm{M}\right)$ in $5 \mathrm{mM}$ Tris- $\mathrm{HCl}$ buffer at $\mathrm{pH} 7.1$ with increasing amounts of DNA. (a) $R=0$; (b) $R=0.2$; (c) $R=0.4$; (d) $R=0.6$; (e) $R=0.8$; and (f) $R=1 . R=[\mathrm{DNA}] /[$ compound $]$.

form of the molecule will be the same as that of its oxidized form. In the present study, it is clear that the potential shift occurs in both NPnl and PLN during the addition of DNA and hence the interactions of the reduced and oxidized forms are not similar. The peak potentials of NPn1 and PLN undergo a slight positive shift with decrease in peak current, which was well distinguished for the NPn1 than PLN. These results indicate that as expected NPn1 were interacted with DNA much efficiently than PLN due to its smaller size which enhanced its solubility. This decrease in current is due to diffusion of an equilibrium mixture of free DNA-bound drug to electrode surface [34].
The Nernst equation for the reversible redox reactions of the free and bound species and the corresponding equilibrium constants for binding of each oxidation state to DNA for an electron process is given as follows:

$$
E_{b}^{0 \prime}-E_{f}^{0 \prime}=0.0591 \log \left(\frac{K_{\mathrm{red}}}{K_{\mathrm{ox}}}\right),
$$

where $E_{b}^{0 \prime}$ and $E_{f}^{0 \prime}$ are the formal potentials of oxidised/ reduced couple in the bound and free forms, respectively, and $K_{\mathrm{ox}}$ and $K_{\text {red }}$ are the binding constants of oxidized and reduced forms to DNA, respectively. The conclusions could 


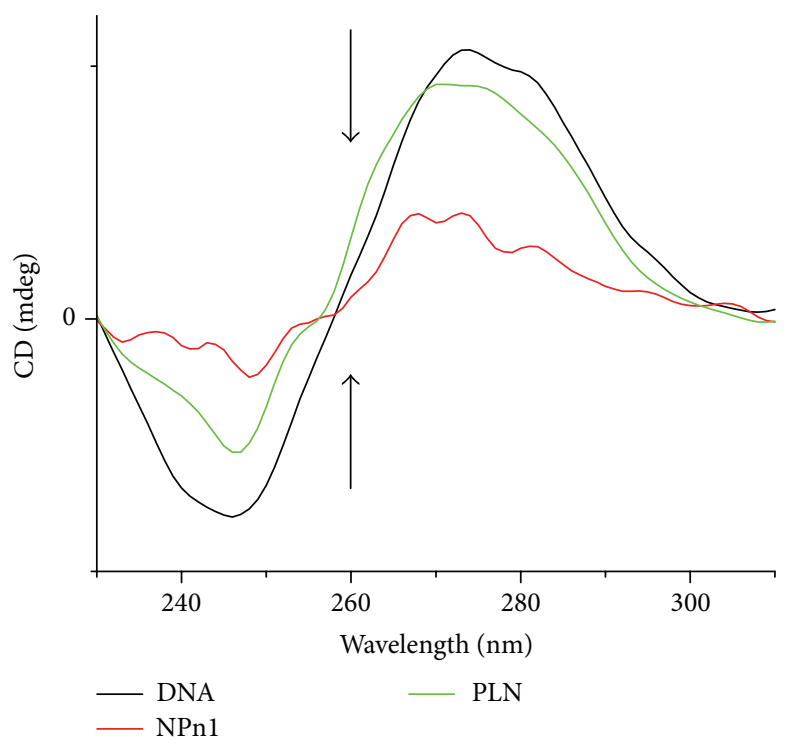

Figure 6: Circular dichroism spectra of HS-DNA $\left(2.4 \times 10^{-4} \mathrm{M}\right)$ in $5 \mathrm{mM}$ Tris-HCl buffer at $\mathrm{pH} 7.1 \mathrm{in}$ the absence and presence of PLN and $\mathrm{NPn} 1$ at a concentration of $\left(5 \times 10^{-4} \mathrm{M}\right)$.

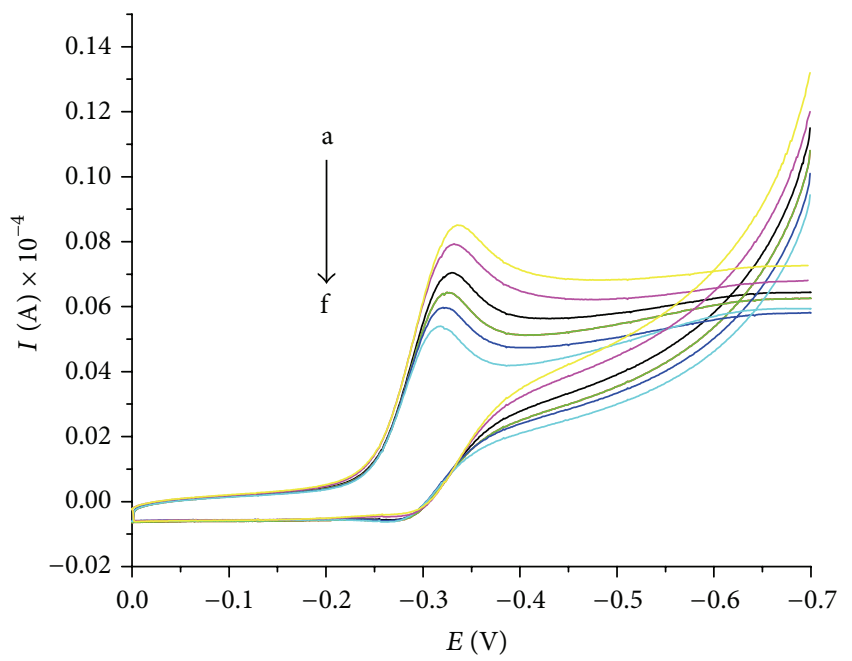

(a)

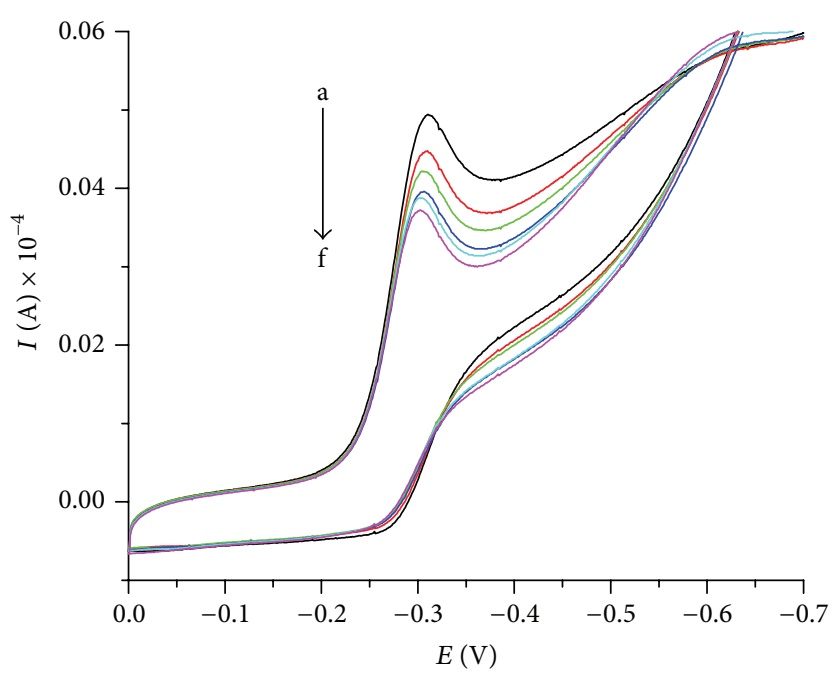

(b)

Figure 7: (a) Cyclic voltammogram of NPn1 $\left(1 \times 10^{-4} \mathrm{M}\right.$ ) in Tris- $\mathrm{HCl}$ buffer $\mathrm{pH}=7.1$ with increasing amounts of DNA. (a) $R=0$; (b) $R=0.2$; (c) $R=0.4$; (d) $R=0.6$; (e) $R=0.8$; and (f) $R=1$ at $100 \mathrm{mVs}^{-1}$ scan rate. (b) Cyclic voltammogram of PLN $\left(1 \times 10^{-4} \mathrm{M}\right)$ with increasing amounts of DNA. (a) $R=0$; (b) $R=0.2$; (c) $R=0.4$; (d) $R=0.6$; (e) $R=0.8$; and (f) $R=1$ at $100 \mathrm{mVs}^{-1}$ scan rate, where $R=$ [DNA]/[compound].

be drawn in the light of Bard's report that both NPn1 and PLN interacted with DNA relatively through weak intercalation mode.

3.3. DNA Cleavage Study. Gel electrophoresis was used to study cleavage of supercoiled pUC18 DNA by the synthesized NPn1 and commercially available PLN. Gels were run in Tris- $\mathrm{HCl} / \mathrm{NaCl}$ buffer $(\mathrm{pH}=7.1)$ and analyzed after ethidium bromide staining in the absence of any external reagent or light.
When circular plasmid DNA is subjected to gel electrophoresis, relatively fast migration is observed for the intact supercoil form (form I). If scission occurs on one strand (nicked circular), the supercoil will relax to generate a slowermoving open circular form (form II). If both strands are cleaved, a linear form that migrates between forms I and II will be generated [35-37].

From gel electrophoresis studies, plumbagin nanoparticles show the change of DNA form I to form II (Figure 8), due to its nanosize which increases the surface area and solubility 


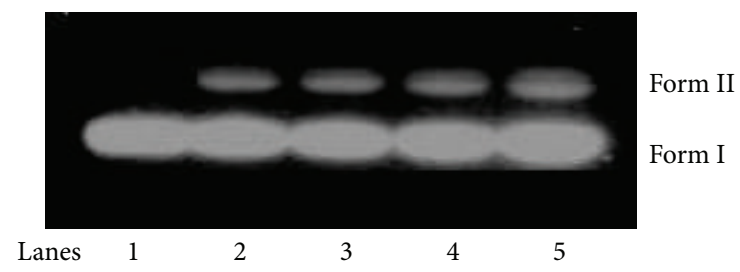

FIGURE 8: Cleavage of plasmid pUC18-DNA treated with increasing concentrations of NPnl after incubation for $2 \mathrm{~h}$ at $37^{\circ} \mathrm{C}$ in Tris$\mathrm{HCl} / \mathrm{NaCl}$ buffer $\mathrm{pH}=7.1$. Lane 1: control DNA; lanes 2-5: DNA+10, 20, 50, and $100 \mu \mathrm{M} \mathrm{NPnl}$, respectively.

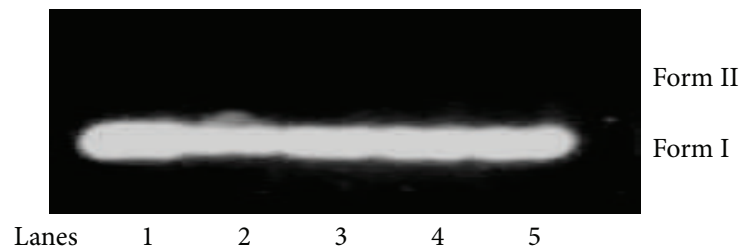

Figure 9: Cleavage of plasmid pUC18 DNA treated with increasing concentrations of PLN after incubation for $2 \mathrm{~h}$ at $37^{\circ} \mathrm{C}$ in Tris$\mathrm{HCl} / \mathrm{NaCl}$ buffer $\mathrm{pH}=7.1$. Lane 1: control DNA; lanes 2-5: DNA+10, 20,50 , and $100 \mu \mathrm{M}$ PLN, respectively.

in incubation of DNA with plumbagin, the supercoiled form of plasmid PUC18 DNA being lengthened without any obvious unwinding, but the DNA mobility for PLN was slightly reduced (Figure 9) [27]. These observed results are also in accordance with the previously studied spectral and electrochemical investigations. All these results clearly indicate that the present NPn1 interacts more significantly than its original counterparts of PLN due its smaller size and enhanced solubility.

\section{Conclusions}

In summary, ultrafine nanoparticles of plumbagin were synthesised successfully by sonochemical methods via controlling the surfactant concentration. They were characterised by UV-Vis, FT-IR, NMR, DLS, AFM, SEM, and XRD techniques and the observed spectral and electrochemical studies indicate that this PLN and Npn1 were partially intercalated to the DNA, in that Npnl intercalated with DNA more significantly compared to the commercial PLN due to its small size which enhanced its solubility in aqueous medium.

\section{Conflict of Interests}

The authors declare that there is no conflict of interests regarding the publication of this paper.

\section{Acknowledgment}

Financial assistance from University Grants Commission (for UPE programme to Madurai Kamaraj University) is gratefully acknowledged.

\section{References}

[1] S. B. Padhye and B. A. Kulakarni, "Studies on the root constituents of Plumbago zeylanica," Journal of the University of Poona. Science and Technology, vol. 44, pp. 27-29, 1973.

[2] J. C. Tilak, S. Adhikari, and T. P. A. Devasagayam, "Antioxidant properties of Plumbago zeylanica, an Indian medicinal plant and its active ingredient, plumbagin," Redox Report, vol. 9, no. 4, pp. 219-227, 2004.

[3] J.-M. Shieh, T.-A. Chiang, W.-T. Chang et al., "Plumbagin inhibits TPA-induced MMP-2 and u-PA expressions by reducing binding activities of NF- $\kappa \mathrm{B}$ and AP-1 via ERK signaling pathway in A549 human lung cancer cells," Molecular and Cellular Biochemistry, vol. 335, no. 1-2, pp. 181-193, 2010.

[4] Y. Chen, X. Lin, H. Park, and R. Greever, "Study of artemisinin nanocapsules as anticancer drug delivery systems," Nanomedicine: Nanotechnology, Biology, and Medicine, vol. 5, no. 3, pp. 316-322, 2009.

[5] C. P. Reis, R. J. Neufeld, A. J. Ribeiro, and F. Veiga, "Nanoencapsulation I. Methods for preparation of drug-loaded polymeric nanoparticles," Nanomedicine: Nanotechnology, Biology, and Medicine, vol. 2, no. 1, pp. 8-21, 2006.

[6] K. N. Thakkar, S. M. Snehit, and Y. P. Rasesh, "Biological synthesis of metallic nanoparticles," Nanomedicine: Nanotechnology, Biology, and Medicine, vol. 6, no. 2, pp. 257-262, 2010.

[7] E. Tomlinson and S. S. Davis, Eds., Site-Specific Drug Delivery, vol. 7, John Wiley \& Sons, Chichester, UK, 1986.

[8] F. Caruso, R. A. Caruso, and H. Möhwald, "Nanoengineering of inorganic and hybrid hollow spheres by colloidal templating," Science, vol. 282, no. 5391, pp. 1111-1114, 1998.

[9] J. H. Bang and K. S. Suslick, "Applications of ultrasound to the synthesis of nanostructured materials," Advanced Materials, vol. 22, no. 10, pp. 1039-1059, 2010.

[10] Z. Zhao, D. Huang, Z. Yin, X. Chi, X. Wang, and J. Gao, "Magnetite nanoparticles as smart carriers to manipulate the cytotoxicity of anticancer drugs: magnetic control and $\mathrm{pH}$-responsive release," Journal of Materials Chemistry, vol. 22, no. 31, pp. 1571715725, 2012.

[11] P. Anand, H. B. Nair, B. Sung et al., "Design of curcuminloaded PLGA nanoparticles formulation with enhanced cellular uptake, and increased bioactivity in vitro and superior bioavailability in vivo," Biochemical Pharmacology, vol. 79, no. 3, pp. 330-338, 2010.

[12] D. Wang, M. S. Veena, K. Stevenson et al., "Liposome-encapsulated curcumin suppresses growth of head and neck squamous cell carcinoma in vitro and in xenografts through the inhibition of nuclear factor $\kappa \mathrm{B}$ by an AKT-independent pathway," Clinical Cancer Research, vol. 14, no. 19, pp. 6228-6236, 2008.

[13] V. Gupta, A. Aseh, C. N. Ríos, B. B. Aggarwal, and A. B. Mathur, "Fabrication and characterization of silk fibroin-derived curcumin nanoparticles for cancer therapy," International journal of nanomedicine, vol. 4, pp. 115-122, 2009.

[14] R. K. Das, N. Kasoju, and U. Bora, "Encapsulation of curcumin in alginate-chitosan-pluronic composite nanoparticles for delivery to cancer cells," Nanomedicine: Nanotechnology, Biology, and Medicine, vol. 6, no. 1, pp. 153-160, 2010.

[15] K. Maiti, K. Mukherjee, A. Gantait, B. P. Saha, and P. K. Mukherjee, "Curcumin-phospholipid complex: preparation, therapeutic evaluation and pharmacokinetic study in rats," International Journal of Pharmaceutics, vol. 330, no. 1-2, pp. 155-163, 2007.

[16] M. M. Yallapu, M. Jaggi, and S. C. Chauhan, "Poly( $\beta$-cyclodextrin)/curcumin self-assembly: a novel approach to improve 
curcumin delivery and its therapeutic efficacy in prostate cancer cells," Macromolecular Bioscience, vol. 10, no. 10, pp. 1141-1151, 2010.

[17] S. Bisht, M. Mizuma, G. Feldmann et al., "Systemic administration of polymeric nanoparticle-encapsulated curcumin (NanoCurc) blocks tumor growth and metastases in preclinical models of pancreatic cancer," Molecular Cancer Therapeutics, vol. 9, no. 8, pp. 2255-2264, 2010.

[18] L. Jiang, Y. Yan, and J. Huang, "Versatility of cyclodextrins in self-assembly systems of amphiphiles," Advances in Colloid and Interface Science, vol. 169, no. 1, pp. 13-25, 2011.

[19] C. W. Lim, O. Crespo-Biel, M. C. A. Stuart, D. N. Reinhoudt, J. Huskens, and B. J. Ravoo, "Intravesicular and intervesicular interaction by orthogonal multivalent host-guest and metalligand complexation," Proceedings of the National Academy of Sciences of the United States of America, vol. 104, no. 17, pp. 69866991, 2007.

[20] J. Zhu, S. Liu, O. Palchik, Y. Koltypin, and A. Gedanken, "A novel sonochemical method for the preparation of nanophasic sulfides: synthesis of $\mathrm{HgS}$ and $\mathrm{PbS}$ nanoparticles," Journal of Solid State Chemistry, vol. 153, no. 2, pp. 342-348, 2000.

[21] K. S. Suslick, Ultrasound: Its Chemical, Physical and Biological Effects, VCH, Weinheim, Germany, 1988.

[22] S.-H. Wu and D.-H. Chen, "Synthesis of high-concentration Cu nanoparticles in aqueous CTAB solutions," Journal of Colloid and Interface Science, vol. 273, no. 1, pp. 165-169, 2004.

[23] X. Li, J. Shen, A. Du et al., "Facile synthesis of silver nanoparticles with high concentration via a CTAB-induced silver mirror reaction," Colloids and Surfaces A: Physicochemical and Engineering Aspects, vol. 400, pp. 73-79, 2012.

[24] B. Aswathy, G. S. Avadhani, S. Suji, and G. Sony, "Synthesis of $\beta$ cyclodextrin functionalized gold nanoparticles for the selective detection of $\mathrm{Pb} 2+$ ions from aqueous solution," Frontiers of Materials Science, vol. 6, no. 2, pp. 168-175, 2012.

[25] P. F. Shi, Q. Jiang, Y. M. Zhao et al., "DNA binding properties of novel cytotoxic gold(III) complexes of terpyridine ligands: the impact of steric and electrostatic effects," Journal of Biological Inorganic Chemistry, vol. 11, no. 6, pp. 745-752, 2006.

[26] H. L. Chan, D. L. Ma, M. Yang, and C. M. Che, "Synthesis and biological activity of a platinum(II) 6-Phenyl-2,2'-bipyridine complex and its dimeric analogue," ChemBioChem, vol. 4, no. 1, pp. 62-68, 2003.

[27] Z.-F. Chen, M.-X. Tan, L.-M. Liu et al., "Cytotoxicity of the traditional chinese medicine (TCM) plumbagin in its copper chemistry," Dalton Transactions, no. 48, pp. 10824-10833, 2009.

[28] V. I. Ivanov, L. E. Minchenkova, A. K. Schyolkina, and A. I. Poletayev, "Different conformations of double-stranded nucleic acid in solution as revealed by circular dichroism," Biopolymers, vol. 12, no. 1, pp. 89-110, 1973.

[29] B. A. Jackson, V. Y. Alekseyev, and J. K. Barton, "A versatile mismatch recognition agent: specific cleavage of a plasmid DNA at a single base mispair," Biochemistry, vol. 38, no. 15, pp. 46554662, 1999.

[30] A. K. Patra, M. Nethaji, and A. R. Chakravarty, "Synthesis, crystal structure, DNA binding and photo-induced DNA cleavage activity of (S-methyl-1-cysteine)copper(II) complexes of heterocyclic bases," Journal of Inorganic Biochemistry, vol. 101, no. 2, pp. 233-244, 2007.

[31] H. Wang, M. Tan, J. Zhu et al., "Synthesis, cytotoxic activity, and DNA binding properties of copper (II) complexes with hesperetin, naringenin, and apigenin," Bioinorganic Chemistry and Applications, vol. 2009, Article ID 347872, 9 pages, 2009.
[32] J. Sun and D. K. Y. Solaiman, "The cyclic voltammetric study of iron-tallysomycin in the absence and presence of DNA," Journal of Inorganic Biochemistry, vol. 40, pp. 271-277, 1990.

[33] A. J. Bard and L. R. Faulkner, Electrochemical Methods, Wiley, New York, NY, USA, 1980.

[34] M. T. Carter, M. Rodriguez, and A. J. Bard, "Voltammetric studies of the interaction of metal chelates with DNA. 2. Tris-chelated complexes of cobalt(III) and iron(II) with 1,10phenanthroline and 2,2'-bipyridine," Journal of the American Chemical Society, vol. 111, no. 24, pp. 8901-8911, 1989.

[35] J. A. Cowan, "Metal activation of enzymes in nucleic acid biochemistry," Chemical Reviews, vol. 98, no. 3, pp. 1067-1088, 1998.

[36] A. Sridhar and J. A. Cowan, "Catalytic hydrolysis of DNA by metal ions and complexes," JBIC Journal of Biological Inorganic Chemistry, vol. 6, no. 4, pp. 337-347, 2001.

[37] E. L. Hegg and J. N. Burstyn, "Toward the development of metal-based synthetic nucleases and proteases: a rationale and progress report in applying the principles of coordination chemistry," Coordination Chemistry Reviews, vol. 173, no. 1, pp. 133-165, 1998. 

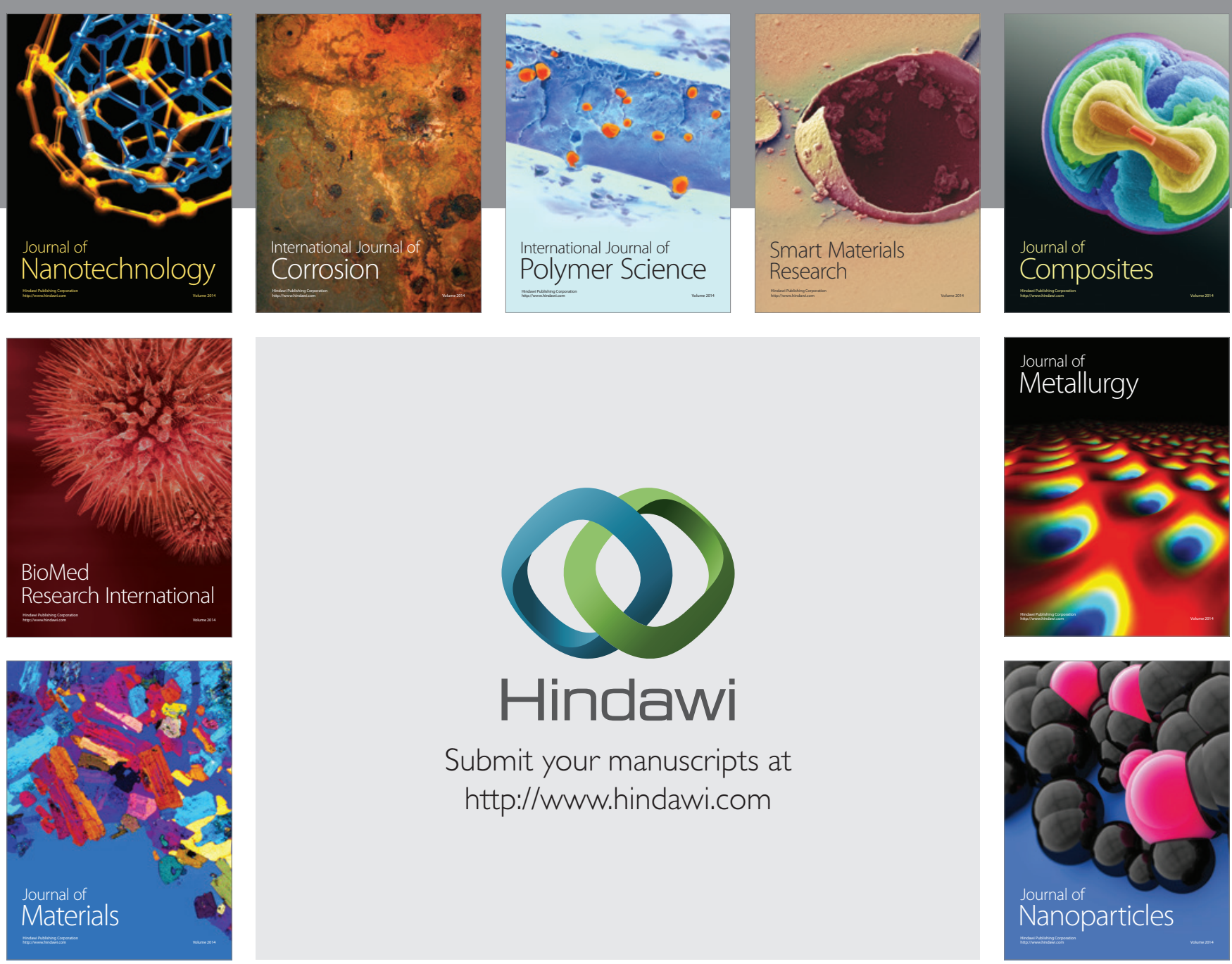

Submit your manuscripts at http://www.hindawi.com
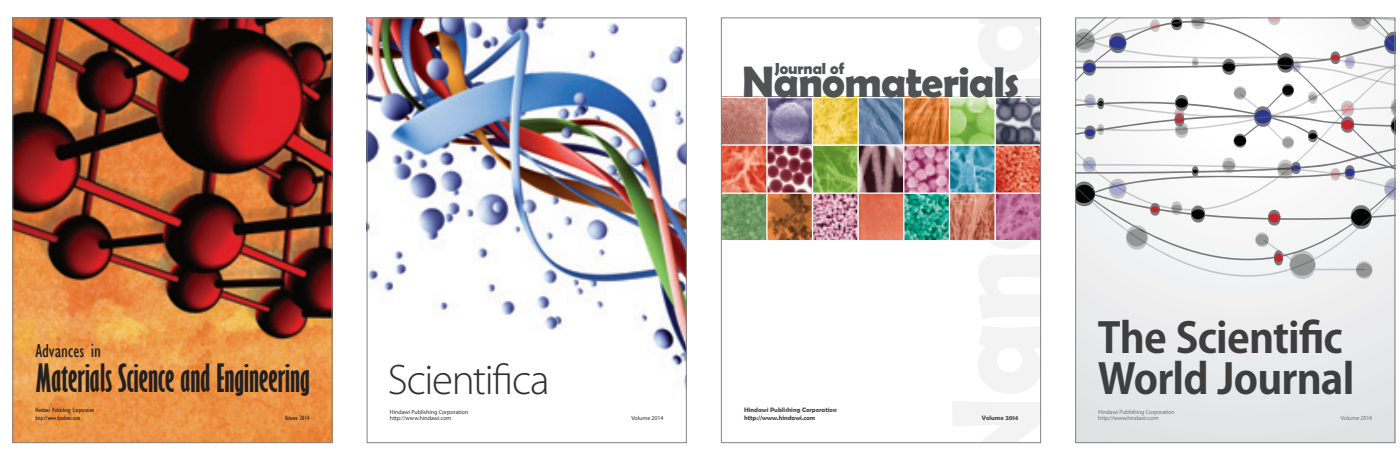

\section{The Scientific World Journal}
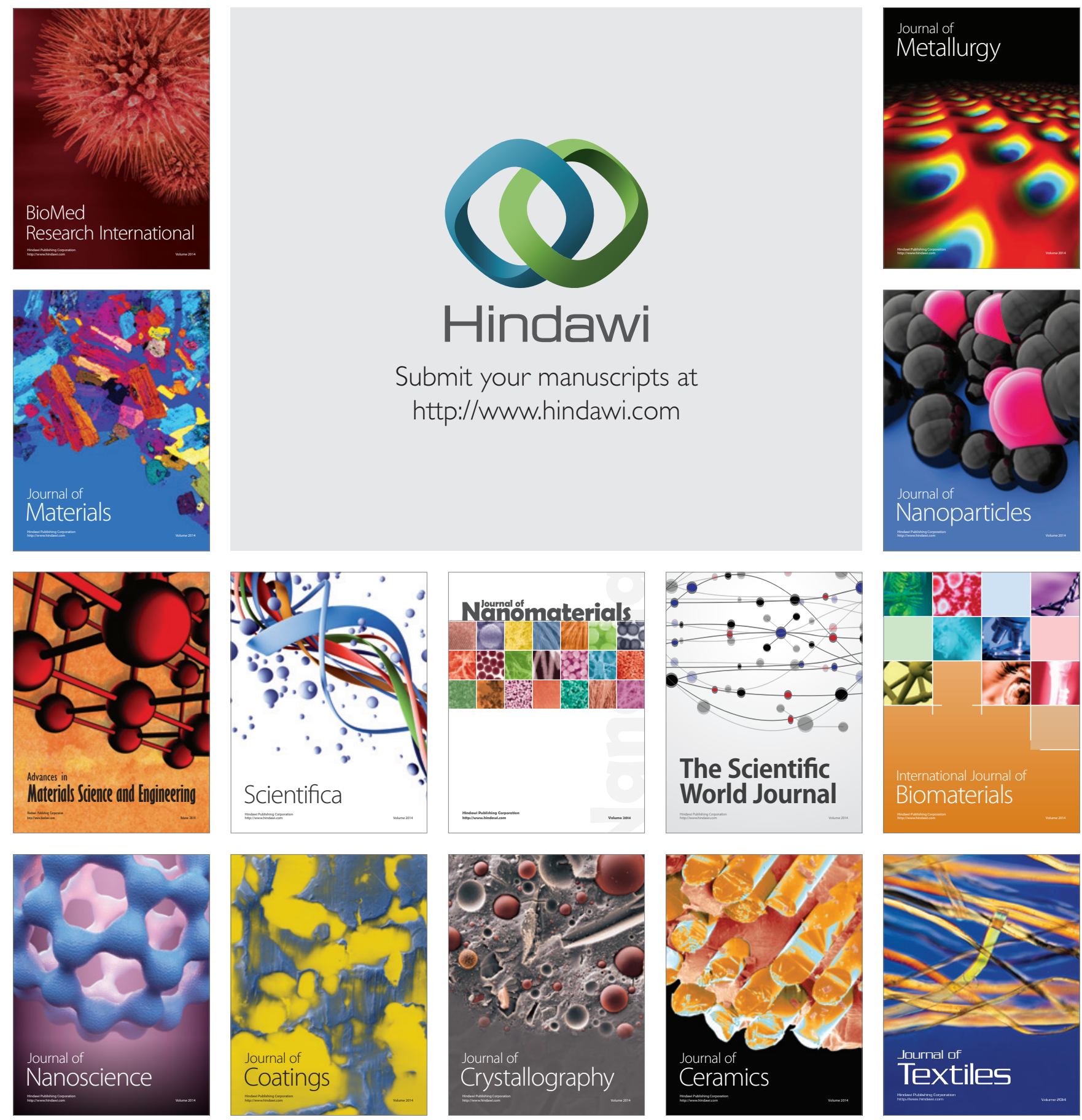